GAPP, número 24, noviembre de 2020

Sección: ESTUDIOS

Recibido: 11-02-2020

Modificado: 12-04-2020

Aceptado: 13-04-2020

DOI: https://doi.org/10.24965/gapp.i24.10776

Páginas: 44-62

\title{
Las leyes de transparencia como vector de la ciudadanía: estudio comparativo de Brasil y España
}

\section{Transparency laws as a vector of citizenship: a comparative study of Brazil and Spain}

\author{
Beatriz Cristina Cari \\ Universidad de São Paulo (Brasil) \\ ORCID: https://orcid.org/0000-0001-9766-8047 \\ beatriz.cari@alumni.usp.br
}

\section{NOTA BIOGRÁFICA}

Graduada en Gestión de Políticas Públicas por la Universidad de São Paulo, con doble grado en Gestión y Dirección Pública por la Universidad de Vigo. Estudiante investigadora de las temáticas de Administración Pública con énfasis en Políticas Públicas y transparencia.

\section{RESUMEN}

Este trabajo tiene como objetivo analizar la aplicación de las leyes de transparencia de Brasil y España, en una perspectiva comparada, buscando conocer qué mecanismos alojados en estas webs facilitan el acceso de la ciudadanía a la información y comprobar, al mismo tiempo, el grado de aplicación de las leyes de transparencia.

Por ello, el tipo de investigación elegida es la descriptiva con abordaje comparativa, y como procedimiento fueron empleados test de usabilidad en los sitios institucionales de transparencia de Brasil y España. En estos test, se evaluaron criterios como usabilidad técnica, información, comunicación y servicios. También se realizó un levantamiento bibliográfico, a través del método de investigación documental, con la intención de provocar una reflexión acerca del objeto estudiado. A partir del análisis preliminar de las bibliografías básicas en el transcurso de este trabajo, se pudo observar que existe relación entre transparencia y ciudadanía, y entender este fenómeno es importante para comprender que las herramientas facilitadoras de transparencia son capaces de influir en las prácticas de un buen gobierno.

\section{PALABRAS CLAVE}

Transparencia; ciudadanía; información; gobierno abierto; buen gobierno.

\begin{abstract}
This paper aims to analyze the application of the transparency laws of Brazil and Spain in a comparative perspective, seeking to know what mechanisms housed in these websites facilitate the access of the citizens to the information and to check, at the same time, the degree of application of transparency laws.

Therefore, the type of research chosen is descriptive with a comparative approach, and as a procedure used usability tests on the institutional transparency sites of Brazil and Spain. In these tests, were evaluated criteria such as technical usability, information, communication and services. We also used the bibliographic, with the documentary research method with the intention of provoking a reflection about the object studied. From the preliminary analysis of the basic bibliographies during this paper, it could
\end{abstract}


be observed that there is a relationship between transparency and citizenship, and understanding this phenomenon is important to understand if the tools that facilitate transparency are capable of influencing the practices of good governance.

\section{KEYWORDS}

Transparency; citizenship; information; open government; good governance.

\section{SUMARIO}

INTRODUCCIÓN. 1. ESTADO DEL ARTE SOBRE CIUDADANIA, TRANSPARENCIA Y BUEN GOBIERNO. 2. BREVE PASAJE HISTÓRICO POR LOS PROYECTOS DE TRANSPARENCIA. 2.1. PROYECTO DE TRANSPARENCIA EN BRASIL. 2.2. PROYECTO DE TRANSPARENCIA EN ESPAÑA. 3. METODOLOGÍA. 4. RESULTADOS. 5. DISCUSIÓN Y ANÁLISIS COMPARATIVO. 6. CONCLUSIÓN. REFERENCIAS BIBLIOGRÁFICAS.

\section{INTRODUCCIÓN}

La idea de transparencia política, está asociada a un fenómeno que fue socialmente construido y que es consecuencia de las relaciones entre los diversos actores, que posee representantes en el ámbito del Estado y en el campo de la sociedad. Esta perspectiva, encuentra la orientación a través de la presuposición sociológica de que las necesidades y los valores sociales se construyen y reconstruyen a través de la dinámica social, que está marcada por la voluntad y el juicio que rigen el comportamiento social, el cual camina en armonía con los procesos históricos que configuran a las sociedades y sus grupos. Porque las necesidades no son homogéneas, tampoco preestablecidas. Al contrario: ellas son plurales y expresan cambios que ocurren política y culturalmente (Figueiredo, 1989 citado por Barros, 2015: 343).

Debray (1994, citado por Barros, 2015: 343) apunta como ejemplo que no siempre la transparencia política ${ }^{1}$ fue juzgada como una necesidad social, sino que hubo un período donde se defendía el secreto de las informaciones políticas, de las acciones del Estado y de sus instituciones. Esto refuerza la idea sociológica de que el motivo que orienta la actuación social está en constante mutación, variando de acuerdo con el contexto histórico y con cada sociedad.

En la actualidad, un indicador de garantía de la ciudadanía es el derecho a la información, tener acceso a la información pública de manera amplia y así ejercer su derecho. Dentro de esta perspectiva, se encuentra el derecho a la información gubernamental y el papel del régimen jurídico, en este contexto, es orientar las relaciones entre Estado y Sociedad, institucionalizando las variadas estructuras informacionales. En ese proceso, las demandas por transparencia y participación del ciudadano en el control social de las actividades del Estado, ganan evidencia en la agenda política y en el nuevo modelo de gestión de la información (Jardim, 2012: 2).

Para Evangelista (2010: 7) es en función de la transparencia que la gestión pública debe permearse, teniendo los gestores públicos el papel de informar a los ciudadanos sobre el resultado de sus acciones en favor de la sociedad. Además, deben considerar las demandas del mundo moderno y globalizado, que exigen cada vez más informaciones, en mayor cantidad y calidad, más sofisticadas y precisas sobre los ejercicios de los gobiernos, el impacto social y económico alcanzado. Es una demanda que surge de diversos sectores: del mercado, de los inversores, de la población en general e incluso de los gobernantes, que requieren datos que posibiliten el control, la evaluación y reestructuración de sus políticas, por lo que, para ellos, se hacen necesarias informaciones eficientes y seguras.

En ese contexto, el modelo de transparencia activa ${ }^{2}$, se está convirtiendo, cada vez más, en un proceso común en la administración pública. Además, la divulgación proactiva de informaciones de interés público, al mismo tiempo de facilitar el acceso del público en general, reduce costos con la prestación de información, al evitar la acumulación de solicitudes sobre temas parecidos.

1 Se refiere a la divulgación de informaciones a respecto de los actos de los poderes públicos y la gestión pública.

2 Se refiere aquella información cuya divulgación ocurre por iniciativa del poder público, siendo publicada por obligaciones legales o no, y que está a disposición independientemente de los requerimientos. 
Para Santos et al. (2017: 50), la aplicación de las leyes de transparencia es un fenómeno que hace efectiva la democracia, pues es capaz de asegurar el derecho de acceso a las informaciones públicas y producidas por el Estado. Esto posibilita a los ciudadanos, la fiscalización y el control del gasto público, y puede, incluso, evitar casos de corrupción. Así, la transparencia es un medio de garantizar al ciudadano mayor participación en los procesos de decisiones, mejorar la legitimidad, la eficacia y la responsabilización de los gestores públicos, lo que deviene en un mayor respeto a las instituciones democráticas y a los derechos.

La ciudadanía carece de un espacio de diálogo y construcción cívica de derechos: para esto cuenta con la participación de diversas instituciones, además de las estatales, de medios eficientes de acceso a la información, y de libertad de expresión y pensamiento para construir sus opiniones, sus pensamientos y expresarlos de manera tal que, contribuyan en las deliberaciones públicas (Vasconcelos Neto, 2015: 9).

Así, teniendo en cuenta este contexto de cambio social y el surgimiento de la pauta de la transparencia, bajo la perspectiva del acceso a la información, como un mecanismo que posibilita la práctica de la ciudadanía y el control social, el foco del presente trabajo está orientado a comprender la usabilidad y facilidad de navegación en los portales de transparencia.

En el contexto de estos portales web, analizaremos la usabilidad como herramienta facilitadora de la transparencia capaz viabilizar acciones del Estado, en lo que se refiere al «buen gobierno». El objetivo es analizar la aplicación de las leyes de transparencia de Brasil y España, en una perspectiva comparada. Lo que queremos es analizar el nivel de usabilidad de los sitios institucionales de los gobiernos de Brasil y España con el propósito de conocer, qué mecanismos alojados en estas webs facilitan el acceso de la ciudadanía a la información y comprobar, al mismo tiempo, el grado de aplicación de las leyes de transparencia. Se analizarán tales aspectos, por medio de la usabilidad de los portales de transparencia.

En el primer apartado, vamos a entender la discusión por detrás de algunos conceptos que rodean la temática de la transparencia y comprehender cómo esta problemática entró en la agenda de investigaciones académicas y por supuesto en la agenda pública.

En el segundo, empezaremos a analizar la historia de la elaboración de las leyes de trasparencia de Brasil y España, lo que nos ayudará a entender si fue un proceso bottom-up o top-down.

A continuación, expondremos los análisis y discusiones a respecto de los test de usabilidad para observar cuánto facilitan o no las páginas web de transparencia en su utilización. Al final, presentaremos las principales conclusiones alcanzadas en este trabajo, suscitando las afirmaciones que utilizamos para la construcción del mismo.

\section{ESTADO DEL ARTE SOBRE CIUDADANIA, TRANSPARENCIA Y BUEN GOBIERNO}

La ciudadanía es un concepto que está intrínsecamente relacionado con la idea de ciudadano y derechos. También se vincula con ser miembro de un Estado y de una colectividad que, al disfrutar de sus derechos, participa de la vida pública y política. El concepto de ciudadanía es complejo y las discusiones abarcan también el acceso a los derechos. La lucha de los movimientos sociales y de la sociedad organizada tiene una importante contribución en la emergencia de una nueva concepción de ciudadanía, la cual está entrelazada a una construcción democrática y de transformación social, que trasciende la reivindicación de acceso e inclusión; es una forma de pertenencia al sistema político, lo que en cierta medida crea una coyuntura para la decisión de este sistema, reinventado a la sociedad (Dagnino, 2004: 104).

Dalmo Dallari $(1998,14)$ nos presenta una visión muy crítica acerca de la Ciudadanía:

A cidadania expressa um conjunto de direitos que dá à pessoa a possibilidade de participar ativamente da vida e do governo de seu povo. Quem não tem cidadania está marginalizado ou excluído da vida social e da tomada de decisões, ficando numa posição de inferioridade dentro do grupo social.

Amartya Shrivastava (2015: 5), define la transparencia como un proceso de conocimiento. Desde una perspectiva directa, se refiere a lo que es fácilmente visible y, desde una perspectiva política, es un fenómeno que se refiere a la confianza, una transición de un gobierno para los ciudadanos, donde es posible compartir pensamientos necesarios para el desarrollo social, y principalmente, es una manera de ver el funcionamiento del gobierno. 
Para Álvarez (2013: 219), una política de transparencia y acceso a la información es el primer paso para lograr la gobernanza responsable, porque es posible observar si los gobiernos y sus agentes actuarán según las normas de la probidad y, así, que sean responsabilizados y reciban las consecuencias correspondientes de acuerdo a sus actos.

En esta discusión es importante también considerar la concepción de ética pública, que se refiere al estudio del comportamiento capaz, responsable y comprometido de los actores dirigidos a los asuntos públicos. Una política de transparencia y buen gobierno, para que sea eficiente, es necesario que vaya más allá de simplemente dirigirse a la administración pública. Es importante también que se involucren a otros actores, como los privados y la sociedad civil que estén relacionados con la acción pública, para que se logre así el funcionamiento del Estado Democrático (Bauman, 2009 citado por Álvarez, 2013: 216).

La transparencia es un factor decisivo para monitorear la responsabilidad del gobierno, y la rendición de cuentas es imprescindible para la estabilidad democrática. Sin esa responsabilidad, la estabilidad democrática no es posible. Por eso, la transparencia y el accountability son los pilares centrales de la buena gobernanza, mutuamente beneficiosos, porque la transparencia alimenta la rendición de cuentas y la responsabilidad sólo sucede a través de la transparencia; tales ideas también están relacionadas con la opinión pública. Así estos conceptos construyen la esencia de la estabilidad democrática (Shrivastava, 2015: 9).

Con la evolución tecnológica, todas estas discusiones sobre transparencia, opinión pública, monitoreo de las acciones públicas, participación y control social se vuelven más palpables dentro del llamado buen gobierno o buena gobernanza. Podemos analizar esos cambios en base a la Nueva Gestión Pública, la cual surge a partir de una discusión que intenta conciliar los antiguos conceptos tan debatidos a lo largo de los años, con las nuevas posibilidades derivadas de los fenómenos tecnológicos.

Debido a ello, la Nueva Gestión Pública es resultado de un movimiento con base en el cuestionamiento de la forma en que están trabajando los agentes públicos, y ante ello la falta de uso de las Tecnologías de Información y Comunicación (TIC) y de las redes sociales, herramientas capaces de promover la participación y la ciudadanía, y que también es capaz de presionar por mayor transparencia por parte de las entidades públicas, facilitando el acceso a los datos al mismo tiempo que se monitorea el comportamiento de los agentes, de acuerdo con los códigos de conducta en que finalmente están las bases del buen gobierno, con apertura para la sociedad y con cambio de paradigma para una sociedad de redes (Ramírez-Alujas, 2011: 104).

Este cambio de paradigma, como ya se ha dicho anteriormente, es paralela a la revolución tecnológica (Criado, 2016: 250). Castells (2001) ya había identificado un fenómeno de la información de la sociedad de red. En la gestión pública este cambio llega con los conceptos de administración electrónica, gobierno electrónico y gobierno digital (Criado, 2009; Heeks, 2006, Kraemer y King, 2003, Scholl, 2014, Yildiz, 2007 citado por Criado, 2016: 250).

Estos conceptos, estaban orientados a solucionar los problemas de eficacia y eficiencia de la Nueva Gestión Pública, además de mejorar la relación con los actores interesados creando portales web y servicios electrónicos, institucionalizando los principios de la gobernanza pública. En la segunda década del nuevo milenio, las transformaciones de las tecnologías sociales se establecen y llevan a la gestión pública la filosofía web 2.0, las redes sociales, ética hacker y los datos abiertos. En este período, el valor de la transparencia, la participación y la colaboración se vuelven también conceptos más robustos. Todos estos cambios crean nuevos paradigmas en lo que concierne a un nuevo modelo de Estado, con administraciones públicas colaborativas o también denominado el nuevo paradigma de la Gobernanza Pública Inteligente (Criado, 2016: 250).

Los debates y la aprobación de leyes que aseguran la transparencia pública en varias partes del mundo han sido fundamentales en la creación de una nueva cultura en la gestión pública acerca de asuntos ajenos a los ciudadanos, que ahora poseen asegurados por ley espacios para la responsabilidad, la transparencia y el control de la corrupción, al mismo tiempo que también tienen mecanismos de presión a nuevas prácticas en los gobiernos (Ramírez-Alujas, 2011: 101, 102).

Las nuevas aplicaciones y herramientas tecnológicas, a su vez, posibilitan el llamado gobierno inteligente que incluye estos espacios arriba citados. Esa inteligencia se lleva a cabo de manera colectiva, a través de los portales de la transparencia, que tiene en su intención la comunicación con el ciudadano, evaluación de los mecanismos digitales y generación de comunidades de aprendizaje que colaboran en la implementación de soluciones a los problemas públicos (Criado, 2016: 256).

La participación de los ciudadanos, en este proceso, es lo que llamamos ciudadanía; proceso que a través de diferentes medios generan conocimiento para soluciones de problemas, posibilitando la 
promoción del compromiso cívico, creación de valor público que se realiza a través de la colaboración directa con la gestión pública, llevando a una mayor transparencia y capacidad de colaboración social (Criado, 2016: 261).

En este punto es necesario volver a la noción de buen gobierno que está directamente asociado al concepto de gobernanza. Tales ideas surgen de la necesidad de ir más allá de la idea de gobierno que está asociado con modelos antiguos y predominantemente jerárquicos (Longo, 2008; Willke, 2007 citado por Ramírez-Alujas, 2011: 104). La gobernanza puede ser entendida como: «el conjunto de arreglos institucionales mediante los cuales se adoptan y ejecutan las elecciones públicas en un entorno social determinado y cada vez más complejo» (Ramírez-Alujas, 2011: 104).

El buen gobierno tiene como propuesta, en su génesis, la necesidad de un gobierno de conectar con fluidez a la sociedad civil, generando una participación social en la elaboración de políticas públicas y en la promoción de un buen gobierno. La propia OCDE $(2003)^{3}$ apunta que todo buen gobierno tiene como pilares: informar, consultar y hacer la participación social. Como consecuencia, surge el gobierno abierto que está relacionado con la transparencia de las acciones de los gobiernos, la accesibilidad de los servicios públicos y la capacidad de respuesta del gobierno en lo que se refiere a los derechos y nuevas demandas y necesidades.

El gobierno abierto es aquel en que entidades privadas, organizaciones de las sociedades civil y ciudadanos pueden conocer, obtener informaciones de forma relevante y comprensible, así como adquirir servicios y realizar transacciones con el gobierno, además de participar en el proceso de toma de decisión. De modo que la transparencia, la rendición de cuentas, la justicia, la equidad, la eficiencia y la eficacia, se convierten en principios del buen gobierno (OCDE policy brief, 2005 citado por Ramírez-Alujas, 2011: 107).

El gobierno abierto, la transparencia y la buena gobernanza, son esenciales para el fortalecimiento de la democracia, pues permiten el escrutinio público, ofrecen mecanismos de control a la corrupción y acumulación excesiva de riqueza, control del poder que está en manos de pocos y posibilita mayores oportunidades de participación ciudadana. Tales medidas, reconocen que un gobierno abierto es condición necesaria, pero no suficiente, para fortalecer el buen gobierno y para conquistar ese objetivo, también se hacen necesarias medidas que aseguren la capacidad de influencia de la sociedad civil (Ramírez-Alujas, 2011: 110).

Esta revisión literaria nos permite caminar por el universo de la transparencia y gobierno abierto, y entender cuántas concepciones están íntimamente entrelazadas a este entorno. Hablar sobre transparencia y buen gobierno es también hablar de democracia, accountability, gobierno abierto, tecnología, conocimiento, participación, control social, ciudadanía y derechos, entre los diversos aspectos destacados sucintamente en ese apartado, que es imprescindible que sean entendidos y trabajados de manera conjunta para que se logren los avances esperados dentro de la gestión pública.

\section{BREVE PASAJE HISTÓRICO POR LOS PROYECTOS DE TRANSPARENCIA}

\subsection{Proyecto de Transparencia en Brasil}

Desde la Constitución Federal de $1988^{4}$, la sociedad brasileña tiene el derecho a la información garantizada, considerada uno de los principales pilares de la democracia moderna, además de ser considerada un derecho civil, político y social que muestra la importancia de manera jurídicamente positivada de la información en las sociedades que siguen el modelo democrático (Jardim, 2012: 2).

La Ley 12.527/2011 o Ley de Acceso a la Información - LAI, según el sitio gubernamental de acceso a la información del Gobierno Federal, regula el derecho que está positivado en la constitución y crea mecanismos que posibilitan a cualquier persona física o jurídica (sin necesidad de presentar motivo) solicitar y recibir datos e informaciones de órganos y entidades públicas, de todos los entes y poderes extendiéndose a los tres Poderes: la Unión, los Estados, Municipios y Distrito Federal, incluyendo los Tribunales de Cuentas y Ministerio Público.

La LAI se originó de un largo proceso, que rodea a la cuestión de la construcción del derecho a la información en Brasil, y tiene su núcleo en la redemocratización del país en 1985, donde se dibujan los primeros

OCDE (2003): Spain: Open Government: Fostering Dialogue with Civil Society. En Public Sector Modernization: Open Government.

${ }^{4}$ Inciso XXXIII del art. $5 .^{\circ}$, en el inciso II del $\S 3 .^{\circ}$ del art. 37 y en el $\S 2 .^{\circ}$ del art. 216 de la Constitución Federal brasileña. 
contornos de ese derecho que se positivó en la Constitución de 1988. A pesar de que, la primera reglamentación constitucional llevó seis años para concretarse, de manera que ocurre lejos del propósito de una ley específica para el acceso a las informaciones gubernamentales, puede observarse en la Ley de Archivos de 1991 que su Capítulo V, está dedicado al «acceso y secreto de los documentos públicos», capítulo revocado posteriormente con la aprobación de la Ley de Acceso a la Información (Jardim, 2012: 6).

A lo largo de los años surgieron una serie de proyectos de ley, tanto en el senado como en la cámara de los diputados, que buscaban reglamentar el derecho de acceso. Proyectos muy influenciados por otras democracias, principalmente México, que pone su ley en vigor en 2003, y Estados Unidos de América que tiene su legislación desde 1966.

Sin embargo, para la aprobación de tal ley, las disputas circundaban principalmente en torno a la burocracia del Poder Ejecutivo Federal. La discusión tuvo su inicio en 2004, originada por diputados del Partido dos Trabalhadores (PT), buscando apoyo de la Controladoria Geral da União (CGU). Así, se inició una discusión que culminó en la creación de un proyecto de ley del Poder Ejecutivo Federal.

Los principales actores responsables en ese debate fueron la CGU, el Conselho de Transparencia Pública e Combate a Corrupção (CTPCC), órgano que poseía representantes de la sociedad civil y del gobierno, y finalmente la Casa Civil, que recibió las propuestas finales. En 2006 el Ministerio de Justicia también realizó su contribución con un proyecto de Ley dirigido a archivos y documentos secretos. Ambos proyectos se dirigieron a la Casa Civil y posteriormente a la Presidencia de la República para llevar a cabo la Ley de Acceso a la Información del Poder Ejecutivo Federal.

En los siguientes años la discusión más intensa se centra en la Casa Civil, con la participación de técnicos de diversos órganos del Ejecutivo Federal. La redacción final del texto de la ley quedó a cargo de la Casa Civil que fue enviada en mayo de 2009 al Congreso Nacional. Gran parte del texto publicado permaneció fiel al texto escrito por la burocracia del Estado (Paes, 2011: 414). La ley fue promulgada el 18 de noviembre de 2011, entrando en vigor seis meses después, y fue regulada por medio del Decreto $\mathrm{n}^{\circ} 7.724$, de 16 de mayo de 2012.

La Ley de Acceso a la Información es consecuencia del esfuerzo de la administración pública, que buscaba traer más transparencia al gobierno, así como disponibilidad de informaciones de carácter público, llevando a cabo este proceso por medio de las obligaciones, plazos y procedimientos para la divulgación de datos. A pesar de que existían leyes anteriores a ésta, que trataban de la temática e intentaban aproximar el Estado a la población, la LAI es considerada vanguardista, pues instituye la obligación de rendir cuentas de todo y cualquier órgano y entidad de la administración directa o indirecta, así como de entidades privadas sin ánimo de lucro que reciba recursos provenientes del Estado, las cuales están obligadas a asegurar la publicidad de las informaciones desde la recepción de los traspasos públicos hasta la destinación de esos recursos. Además, la ley establece rutinas para la atención del ciudadano interesado, a la vez que organiza y protege el trabajo de los funcionarios públicos.

La LAl tiene como directrices la publicidad y la transparencia de las informaciones. En este contexto, el secreto es visto como una excepción. Así, la información que está bajo tutela del Estado es siempre pública, debiendo su acceso ser restringido sólo en casos específicos y, aun así, por determinado período de tiempo, que puede ser 5,15 y 25 años, cuando son clasificadas como reservada, secreta y ultrasecreta, respectivamente. Estas informaciones se refieren a la información clasificada por autoridades imprescindibles para la protección del Estado y la sociedad, como datos personales, datos relativos a la persona natural, vida privada e imagen de las personas; estas son las únicas excepciones que no pueden estar sobre el régimen de la transparencia.

Como un medio para facilitar el acceso a las informaciones, la LAl instituye por medio del artículo 9, el deber del Estado de la creación de un punto de contacto entre la sociedad y el sector público. Así, se instaura el Servicio de Información al Ciudadano (SIC) que tiene como funciones: proporcionar la atención y orientación al ciudadano con relación a las solicitudes de informaciones; informar sobre el proceso de tramitación de los documentos y requerimientos de acceso a la información; y recibir y registrar las solicitudes de acceso y responder a los pendientes.

Además, se determinó que cada órgano y entidad del poder público debe realizar la estructuración de ese sector con el objetivo de hacer efectivo el derecho de acceso a la información, teniendo obligatoria la instalación del SIC por lo menos en su sede, en un local de fácil identificación y acceso.

Se desarrolló también el Sistema Electrónico del Servicio al Ciudadano (e-SIC), sistema online que centraliza las entradas y salidas de los pedidos realizados al Poder Ejecutivo Federal. El objetivo de este portal es organizar y facilitar los procedimientos, desde la perspectiva del ciudadano como de la administración 
pública. Además, el e-SIC posibilita que cualquier persona encamine solicitudes de acceso a la información para las organizaciones del gobierno Ejecutivo Federal, lo que permite también consultas a las respuestas recibidas, presentar reclamaciones, entrar con recursos, entre otras posibilidades.

\subsection{Proyecto de Transparencia en España}

El contexto de construcción de la Ley de Transparencia española, a su vez, está influenciado por el discurso del Rigth to Know, que también está presente en la construcción de otras legislaciones en Europa (Piñar Mañas, 2014: 6). Para Cotino-Hueso (2014: 242) es también el resultado de una inercia histórica, política y social, además de una necesidad jurídica de acceso a la información pública, pero también de una consideración de este derecho como fundamental.

El autor recuerda que después de mayo de 1968, en el que hubo una ola de participación que influenció en legislaciones y constituciones, diversos Estados europeos pasaron a reconocer el derecho de acceso a la información. Entre estos Estados se encuentran: Austria, Bélgica, Finlandia, Grecia, Países Bajos, Portugal, Suecia y, desde 2004, Noruega. Este fenómeno influye también en el artículo 105 de la Constitución Española ${ }^{5}$ (Cotino-Hueso, 2014: 242).

En el año 2000, este proceso se intensifica en Europa con los Países Bajos y nórdicos que pasan a solicitar el derecho de acceso de las informaciones de la Unión Europea, es decir, que la Unión Europea sea más transparente en sus decisiones y dispongan las informaciones a los países miembros, a través del reconocimiento del derecho fundamental de acceso a la información y la buena administración, prevista en el artículo 41 "Derecho a una buena administración" y en el artículo 42 "Derecho de acceso a los documentos", de la Carta de Derechos Fundamentales de la Unión Europea, la cual pasa a tener valor jurídico desde diciembre de 2007, y que entra en vigor en 2009. A pesar del contexto internacional, España todavía no había regulado el derecho de acceso a la información como un instrumento de ley porque aún no había desarrollado la idea de derecho fundamental en lo que se refiere a la transparencia y buen gobierno (CotinoHueso, 2014: 242).

El Partido Socialista Obrero Español, desde 2004, inicia la pauta en su programa electoral, pero acaba por chocar con una realidad burocrática interna, que poco poseía los valores de la transparencia e, incluso, con líderes políticos que defendían que el mantenimiento de la opacidad era también el mantenimiento del poder. El intento de cambio del PSOE, en este aspecto, representó un factor importante en la discusión de transparencia en España (Villoria, 2015: 89).

Posteriormente la pauta de la transparencia se convierte en marketing electoral. En 2011, el Partido Popular pasa a promover la transparencia en su programa, ya que había visto los créditos electorales, prometiendo lo siguiente:

Aprobaremos con carácter inmediato y de acuerdo con los principios que inspiran el Convenio Europeo sobre Acceso a los Documentos Públicos, una ley de transparencia, acceso a la información pública y buen gobierno. La ley abordará desde una perspectiva integral la transparencia como un derecho de los ciudadanos y como un principio básico de actuación de todas las administraciones públicas, garantizando de manera ponderada el derecho a la protección de datos de carácter personal y salvaguardando siempre el interés general (Partido Popular. Programa Electoral Elecciones Generales, 2011 citado por Villoria, 2015: 97).

Durante los debates para la investidura del presidente de Gobierno, Mariano Rajoy Brey defendía que, entre sus iniciativas más relevantes, se encontraría la aprobación de la Ley de Transparencia en el primer trimestre de 2012 «como un derecho de los ciudadanos y un principio básico de la actuación de las administraciones». El partido también se comprometió a realizar el proceso de construcción de la ley, considerando consultas a través del sitio web del gobierno (Cotino-Hueso, 2014: 245).

Las promesas fueron cumplidas: el anteproyecto fue sometido a consultas públicas, hubo una considerable movilización con 78.000 visitas al sitio web y 3.600 observaciones. Los temas más debatidos fueron:

5 Constitución Española artículo 105: Participación de los ciudadanos: Artículo 105. La ley regulará: a) La audiencia de los ciudadanos, directamente o a través de las organizaciones y asociaciones reconocidas por la ley, en el procedimiento de elaboración de las disposiciones administrativas que les afecten. b) El acceso de los ciudadanos a los archivos y registros administrativos, salvo en lo que afecte a la seguridad y defensa del Estado, la averiguación de los delitos y la intimidad de las personas. c) El procedimiento a través del cual deben producirse los actos administrativos, garantizando, cuando proceda, la audiencia del interesado. 
La ampliación de los sujetos obligados a la Casa Real, los partidos políticos, los sindicatos, las organizaciones empresariales y todas las personas jurídicas privadas que gestionan fondos públicos; en el caso de falta de respuesta en plazo, la separación del reconocimiento del derecho de acceso a la información como derecho fundamental, la separación al silencio negativo en caso de falta de respuesta en plazo; y la demanda de creación de un órgano verdaderamente independiente como garantía de la efectividad de la Ley (Villoria, 2015: 97).

En las audiencias hubo unanimidad de los especialistas del Centro de Estudios Políticos y Constitucionales (CEPC), al que se consultó el texto legislativo en relación a las propuestas de ampliación de los temas de obligaciones con respecto a la Casa Real, los partidos políticos, los sindicatos y las asociaciones de empresarios, así como la necesidad de incluir sanciones para casos de no respetar normas, como de publicidad activa y pasiva y también la necesidad de un órgano de control independiente (Villoria, 2015: 97).

En paralelo en este proceso fue creada la Comisión para la Reforma de las Administraciones Públicas (CORA), que tenía como responsabilidad hacer proposiciones para mejorar la eficiencia y eficacia de las actividades públicas. Al tratar de la Ley de Transparencia, Acceso a la Información Pública y Buen Gobierno, hicieron importantes contribuciones al proyecto, como: «la creación de una Central de Información, que termine con la dispersión existente en las fuentes de información pública en materia presupuestaria, financiera y económica y con los diferentes criterios aplicados a la hora de dar y ofrecer los datos». Para la comisión esta medida mejoraría la eficiencia en la búsqueda por informaciones, la calidad y cantidad de datos públicos, generaría más transparencia y confianza en las informaciones ${ }^{6}$ (CORA, 2013: 14).

El proyecto final fue presentado el 3 de agosto de 2012 en el Congreso de diputados y fue publicado el 7 de septiembre del mismo año. El Congreso aprobó el texto y envió al Senado un año después, el 18 de septiembre de 2013. El 26 de noviembre de 2013, el Senado aprobó la ley con enmiendas y el 5 de diciembre de 2013, la Ley fue aprobada definitivamente por el Congreso (Cotino-Hueso, 2014: 245).

La Ley de Transparencia, Acceso a la Información Pública y Buen Gobierno (Ley 19/2013) determina que la información debe ser divulgada en sus correspondientes sedes electrónicas o páginas web, de modo que la Administración General del Estado debe desarrollar un Portal de la Transparencia, así como el resto de los órganos, o incluir la información en su sitio o sede electrónica. En este sentido, la ley también determina que la Administración general del Estado, comunidades autónomas y entes locales pueden trabajar de forma cooperativa con el fin de integrar las informaciones, siendo posible portales comunes que dispongan de información relativa a los actos administrativos relacionados con la economía y el presupuesto, el cumplimiento de contratos, convenios, pedidos de gestión, subvenciones, cuentas e informes de auditoría, compensación, compatibilidad, declaraciones de activos e información estadística (Cotino-Hueso, 2014: 249).

La ley también prevé que todos los entes públicos deben divulgar activamente las informaciones de forma actualizada y dinámica, lo que no es suficiente para el cumplimiento de la idea de transparencia. Por eso, la ley también establece la facilidad del suministro de la información directa de bases de datos administrativos, y que dicha información esté estructurada y configurada de manera que facilite su acceso y tratamiento.

La construcción de la ley tiene en su núcleo un concepto muy generoso de la posibilidad de acceso a toda y cualquier información pública, donde se puede acceder a todo el contenido. Sin embargo, la misma ley en su artículo 18, que trata de las causas de inadmisión, también prevé que no se tendrá acceso a «la información en curso de elaboración o de publicación general; la información auxiliar o de apoyo como notas, borradores, opiniones, resúmenes, comunicaciones e informes internos o entre órganos o entidades administrativas». Y es importante también tener en cuenta, que se excluye el acceso a la información cuya divulgación dependa de una acción de repetición del proceso.

El artículo 14 de la Ley también limita el acceso a la información en lo que se refiere a las siguientes temáticas:

La seguridad nacional, la defensa, las relaciones exteriores, la seguridad pública, la prevención, investigación y sanción de los ilícitos penales, administrativos o disciplinarios, la igualdad de las partes en los procesos judiciales y la tutela judicial efectiva, las tareas administrativas de la política económica y monetaria, el secreto profesional y la propiedad intelectual e industrial,

6 COMISIÓN PARA LA REFORMA DE LAS ADMINISTRACIONES PÚBLICAS (CORA) (2013): Reforma de las Administraciones Públicas. Gobierno de España: Ministerio de Hacienda y Administraciones Públicas; Ministerio de la Presidencia. 
la garantía de la confidencialidad el secreto requerido en procesos de toma de responsabilidad, la protección del medio ambiente (Cotino-Hueso, 2014: 251).

Es posible observar que el contexto de construcción de las leyes de transparencia de Brasil y España ocurren a partir de perspectivas distintas, a pesar de que la ley brasileña fue aprobada dos años antes de la española. En Brasil, la ley es el resultado de un esfuerzo técnico burocrático que entiende la necesidad de una norma que regule una brecha constitucional, fundamentando la ley de la transparencia. En España, la ley se inserta en un contexto internacional geográfico que influye en la construcción de esta. Pero ambas leyes fueron resultado de procesos top-down.

\section{METOdOLOgÍA}

En este trabajo hemos analizado el nivel de usabilidad de los sitios institucionales de los gobiernos de Brasil y España, con el propósito de conocer qué mecanismos alojados en estas webs facilitan el acceso de la ciudadanía a la información y comprobar, al mismo tiempo, el grado de aplicación de las leyes de transparencia.

La metodología consiste en el método comparativo, elegido porque permite una aproximación de los casos posibilitando articular teoría y evidencia empírica. El objetivo de esta metodología consiste en una generalización empírica y verificación de hipótesis, además como ventaja el método permite la comprensión de fenómenos desconocidos a partir de los conocidos, su explicación e interpretación, el aprendizaje de nuevos conocimientos, subrayar lo característico de fenómenos conocidos, sistematizar la información diferenciando peculiaridades en casos similares (León y Garza, 2014: 229).

Los casos de Brasil y España fueron elegidos por la aproximación temporal de aprobación de las leyes; Brasil en 2011 y España en 2013, y por tener sus discusiones en épocas muy próximas. Además, los dos casos son pertinentes por pertenecer a contextos políticos, sociales, económicos y geográficos distintos, si bien mantienen características propias de la cultura iberoamericana. En este sentido, resulta interesante comparar tales contextos para enriquecer la comprensión sobre la temática, además de entender cómo fue el debate sobre transparencia trazando algunos paralelismos.

Como procedimiento, hemos aplicado test heurísticos de usabilidad en los sitios de transparencia de Brasil y España. El estudio de la usabilidad ayuda a interpretar el grado de facilidad con que los usuarios interactúan con el sitio web, considerando factores tales como la ubicuidad, diseño, eficiencia, funcionalidad y fiabilidad (Bouzas y Mahou, 2013: 264).

En estos test fueron evaluados algunos criterios, como la usabilidad general, que tiene como objetivo analizar la estructura del portal, como su aspecto y facilidad de navegación; la oferta informativa que tiene que ver con el conjunto de datos disponibles acerca del interés público (Bouzas y Mahou, 2013: 265); los servicios que el portal ofrece, analizando si estos son fácilmente comprensibles, y si poseen una estructura completa; la comunicación y participación ciudadana a través de medios multidimensionales, que facilita la interacción y colaboración con los usuarios (Bouzas y Mahou, 2013: 264) y que permite observar si el portal poseen una buena comunicación con el usuario, si hay pestañas de atención al ciudadano, herramienta de discusiones y debates, buen uso de las redes sociales. Y finalmente, los servicios, que es el conjunto de prestaciones de servicios ofrecidos online (Bouzas y Mahou, 2013: 264) alojados en el portal que nos permiten conocer su nivel de desarrollo, esto es, si el servicio es tramitado completamente a través de internet $y$, por lo tanto, accesible.

La técnica es una adaptación de los test que Bouzas y Mahou (2013: 259) aplicaron al estudio de los portales web de los servicios autonómicos de salud españoles que tenía como objetivo «sugerir un método con el cual analizar cualitativamente de forma integral un sistema de provisión de servicios y atención al ciudadano descentralizado territorialmente, atendiendo a las prestaciones de accesibilidad, usabilidad, oferta informativa y de servicios, y mecanismos de comunicación facilitados.» A partir de tales referencias, fue posible ajustar los test para analizar la facilidad de interacciones de los usuarios con los portales de la transparencia, de manera que, podemos observar si hay mecanismos para adherencia o no, de los portales para la práctica de la ciudadanía, además de comprender si los portales cumplen con sus objetivos dispuestos en sus normativos.

En las siguientes tablas se pueden apreciar los criterios heurísticos utilizados para analizar los portales de la transparencia: 
GAPP. Nueva Época - N. 24, noviembre 2020 - ISSN: 1989-8991 - DOI: https://doi.org/10.24965/gapp.i24.10776 - [Págs. 44-62]

TABLA 1. Contenido del test de usabilidad general

\section{TEST HEURÍSTICO - USABILIDAD GENERAL}

\section{BUSCABILIDAD}

Posicionamiento en motores de búsqueda. Se puntúa según posición tras una búsqueda tipo «TRANSPARENCIA + (nombre del gobierno)».

Ubicación de la página en sede propia o dependencia de la sede de la Administración a la que pertenece.

\section{IDENTIDAD}

Presencia de un logo que identifique la web de acceso y posición prominente en home-page.

Persistencia del logo en páginas secundarias (se desciende hasta tres niveles en la jerarquía de contenidos y se comprueba).

Disponibilidad de tagline (texto con nombre de la organización y/o propósito de ella claramente ubicado).

Etiqueta de «bienvenida» / «quiénes somos (about us)».

\section{DISEÑO-ESTILO}

Comprensibilidad global del sitio (la home-page ofrece una idea clara del sitio y qué se puede hacer).

Identidad de la estructura macro (equilibrio entre jerarquía de contenidos y facilidad de uso) y micro (reflejo de una estructura lógica y jerarquía coherente en páginas secundarias).

Impresión amigable del sitio.

Los headings principales son claros y descriptivos. Calidad del etiquetado de los contenidos (textual e iconos) / consistencia y facilidad de identificación de los links / visibilidad adecuada (ubicación).

Contenidos críticos resaltados (uso adecuado de los formatos que enfatizan los contenidos importantes a través de colores, banners, ventanas especiales, etc.).

La información se despliega claramente por categorías y muestra coherencia.

Diferenciación clara en la home-page entre contenidos de carácter informativo y servicios.

Disponibilidad de indicación básica de los contendidos principales (menú permanente en diferentes niveles).

Dispone de catálogo de servicios disponibles on line (en home-page).

Facilidad de acceso a contenidos con perfil personalizado (ciudadanos; profesionales; administraciones) desde la home-page.

Consistencia / coherencia en uso de estilos y colores.

Legibilidad clara de los textos en contraste con color de fondo.

Legibilidad de textos con tamaño de caracteres adecuado / espaciado cómodo para lectura.

Disponibilidad de ventanas para desplegar contenidos multimedia (no deben obstaculizar la navegación).

\section{NAVEGABILIDAD}

Peso real de descarga de la página de inicio. Puede hacerse la prueba calculando el tiempo de descarga de la home-page (menos de 5 segundos).

Verificación de la capacidad de lectura de home-page sin necesidad de scroll (teniendo en cuenta una resolución media actual de pantalla en 1024x768). Es importante que los contenidos críticos no queden por debajo de la línea de corte de pantalla.

Se verifica el diseño líquido (cambiando la resolución de la pantalla a 800x600 no es necesario scroll horizontal y no hay cortes que impidan la visibilidad de los contenidos).

Elementos obstaculizadores de la navegación (flash; mapas de bists; pop-ups; ads; plug-ins). 
GAPP. Nueva Época - N. 24, noviembre 2020 - ISSN: 1989-8991 - DOI: https://doi.org/10.24965/gapp.i24.10776 - [Págs. 44-62]

\section{TEST HEURÍSTICO - USABILIDAD GENERAL}

Disponibilidad de la página en varios idiomas (inglés).

Disponibilidad de intranet o un entorno virtual exclusivo de navegación y distinción del entorno destinado al público general.

Uso razonable de imágenes y adecuada descarga de ellas que no entorpezca la navegación (capacidad para deshabilitar las imágenes).

Disponibilidad de motor de búsqueda propio: valoración de su accesibilidad y prestaciones (incluye búsqueda avanzada).

Disponibilidad de mapa web.

Mide la posibilidad de acceder a todas las áreas del sistema y regresar sin pérdida. Disponibilidad de ayudas a la navegación alternativas al mapa web (ej. Función de ayuda; Visita guiada/vitual; Camino de migas / breadcrumb trail; estás en...).

Conexión (en páginas secundarias) del logo de la entidad con home-page.

Los links facilitan la navegación (disponibilidad acorde con los contenidos de las páginas sin generar confusión / desorientación).

Facilita la descarga de programas que mejoran la experiencia de navegación del usuario (acrobat; quicktime, etc.).

Disponibilidad de ventana de acceso rápido a contenidos de demanda frecuente.

\section{SEGURIDAD}

Proporciona información sobre protección de datos y formularios (cesión / revocación de la cesión de datos) relacionados con ello.

Disponibilidad de navegación con certificado digital.

Disponibilidad de link para solicitar certificado digital a un proveedor (confiabilidad).

Fuente: Bouzas y Mahou (2013: 268)

TABLA 2. CONTENIDO DEL TEST DE OFERTA INFORMATIVA

\section{TEST HEURÍSTICO - OFERTA INFORMATIVA}

\section{INSTITUCIONAL Y DEL SISTEMA DE INFORMACIÓN}

Significación del provisor de servicios de información (departamento del Estado); funciones; estructura organizativa misión; objetivos; competencias; gestión y funcionamiento del sistema.

Normativa básica del sistema; derechos y deberes.

Descripción de niveles de prestación de servicio.

Información sobre directorio (email / correo postal / web / teléfono; fax) de responsables de la entidad (nombre; cargo).

Respuesta a preguntas frecuentes.

\section{CATÁLOGO / RELACIÓN DE SERVICIOS}

Consulta y gestión de datos personales.

Solicitud de la información.

Si es recibirla por el sistema con avisos por correo electrónico, por correspondencia física o cita para consultar personalmente.

Procedimiento de consultar el responsable por la respuesta y el logro del tiempo. 
GAPP. Nueva Época - N. 24, noviembre 2020 - ISSN: 1989-8991 - DOI: https://doi.org/10.24965/gapp.i24.10776 - [Págs. 44-62]

\section{TEST HEURÍSTICO - OFERTA INFORMATIVA}

Procedimiento de petición de una nueva respuesta.

Procedimiento de consultar el responsable por la respuesta del recurso y el logro del tiempo.

Procedimiento para formular reclamaciones y sugerencias.

\section{OTRAS ENTIDADES}

Información sobre asociaciones profesionales que trabajan con transparencia y temas relacionados.

Información sobre entidades y organismos de las Administraciones Públicas e internacionales.

\section{REPOSITORIOS DOCUMENTALES}

Disponibilidad de servicios de biblioteca y centros de documentación.

Fuente: Bouzas y Mahou (2013: 270)

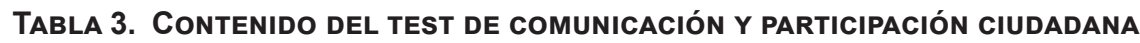

\section{TEST HEURÍSTICO - COMUNICACIÓN Y participación ciudadana}

\section{ENLACE}

Enlace directo al espacio de participación ciudadana con una etiqueta o heading clara y descriptiva, fácil de identificar, visible y consistente ( «gobierno abierto», «participación ciudadana», "comunicación», «atención ciudadana», «portal ciudadano»...).

Contenidos y servicios - El enlace integra los principales contenidos y servicios de participación ciudadana.

\section{ATENCIÓN CIUDADANA}

Chat o asistente Virtual - Disponibilidad y calidad (diseño y funcionamiento) de servicio de asistencia virtual.

E-mail - Dispone de dirección de e-mail.

Buzón virtual - Dispone de un buzón virtual a través del cual formular dudas / solicitar información.

\section{GOBIERNO ABIERTO}

Blogs - Enlace a sitios para el debate y la participación ciudadana Criados tanto por la ciudadanía como por la administración.

Encuesta / opinión - Mecanismos de recogida de opiniones mediante cuestionarios online.

Foros - Espacios, tanto de la ciudadanía como de la administración, de debate, consulta, propuestas, votaciones, comentarios a propuesta del ciudadano y administración.

Información - Enlaces a información sobre participación ciudadana (jornadas, cursos, censo de asociaciones, normativa, órganos de participación, centros o espacios).

Mapas colaborativos - Herramientas que recogen y publican de forma colaborativa datos sobre sucesos, hechos o eventos que tienen lugar en un espacio determinado.

Quejas y sugerencias - Tramitación de quejas y sugerencias a través de formulario.

Plataformas de Open data - Compartición de datos entre ciudadanos y administración.

Red social - Atención y participación ciudadana a través de cuenta propia en las principales red/es social/es y en red social propia. 
GAPP. Nueva Época - N. 24, noviembre 2020 - ISSN: 1989-8991 - DOI: https://doi.org/10.24965/gapp.i24.10776 - [Págs. 44-62]

TABla 4. Contenido del test de SERvicios

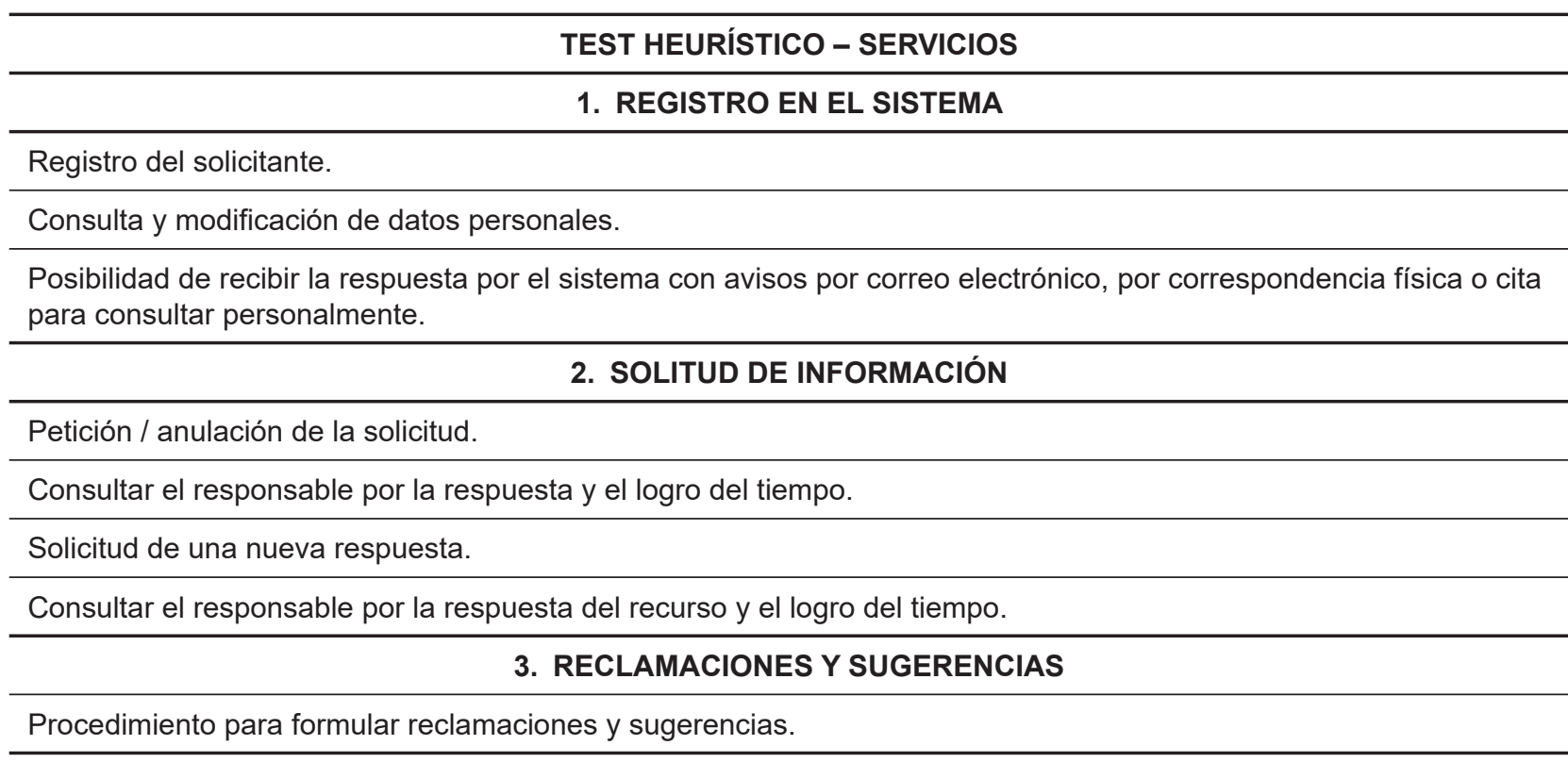

Fuente: Propia a partir de Bouzas y Mahou (2013: 271).

\section{RESULTADOS}

La Ley de Transparencia brasileña prevé que todos los órganos públicos, desde los municipales hasta los federales, necesitan poseer un portal propio cuyo objetivo sea ofrecer informaciones. Sin embargo, la Controladoria Geral da União y el Ministério da Transparência, que son los órganos responsables del monitoreo del cumplimiento de la Ley, poseen el Portal de la Transparencia (http://www.transparencia.gov.br). Este portal tiene como foco el suministro de informaciones del Poder Ejecutivo de la esfera Federal, en el cual pueden ser encontradas herramientas como el Sistema Eletrônico de Informação ao Cidadão (e-SIC), portal intranet donde se puede solicitar cualquier información referente a los órganos del ejecutivo de la Esfera Federal, el Portal Brasileiro de Dados Abertos y el Sistema de Ouvidorias do Governo Federal (e-Ouv).

Así, el Portal de Transparencia posee un sistema que dirige a otros sistemas interconectados de la Ley de Transparencia, como: el Portal Acceso a la Información, el Portal da Controladoria Geral da União, el Portal Governo Aberto, entre otros. De este modo, el análisis de los test heurísticos tiene su foco en el Portal da Transparência y en la herramienta Sistema Eletrônico de Informação ao Cidadão (e-SIC) que es el principal servicio de Transparencia previsto en la Ley.

La Ley de Transparencia de España, a su vez, establece que la administración general debe proveer un Portal de Transparencia, bajo la tutela del Ministerio de la Presidencia, así como las administraciones de las comunidades autónomas y las ciudades Celta y Melilla, y de las entidades locales que deben poseer sus propios portales, donde tienen que colgar la información de mayor interés para los usuarios. En este aspecto, las comunidades autónomas y entidades que forman parte de la administración local pueden aportar medidas independientes para el cumplimiento de la publicidad activa.

El Portal de la transparencia del gobierno central, que será nuestro instrumento de análisis, debe poseer informaciones de toda Administración General del Estado, de ministerios y organismos vinculados. Otros organismos tales como agencias estatales, entidades públicas empresariales y de Derecho Público poseen autonomía para la realización práctica de la transparencia.

Si no se encuentra la información deseada, siempre que esté dentro de los parámetros arriba citados, se puede solicitar tal información, por medio del sistema de clave de identificación, solicitar por correo postal y talleres de registro.

Con relación al análisis de los test heurísticos, el primero es sobre la usabilidad general. Empezando por Brasil, la puntuación general del Portal fue 74 de 97 puntos máximos, siendo los dos primeros criterios de buscabilidad e identidad con una puntuación máxima de 5 y 8 puntos respectivamente. 
En el tercer criterio, diseño-estilo, se puntuó 33 de 39, que era el máximo, y en el cuarto criterio, de navegabilidad, la puntuación fue 27 , de un máximo de 37 puntos, principalmente porque hay pop-ups que dificultan la navegación, así como la inexistencia de otros idiomas, además de la lengua portuguesa.

El quinto y último criterio, seguridad, es el más crítico de todos, pues el portal no ofrece protección de datos, certificado digital o enlace de certificado. La seguridad de la web es un campo de la gestión pública que sigue siendo muy nuevo en Brasil.

España, a su vez, en lo que se refiere a la usabilidad general puntuó 77,5 puntos de un total de 97 puntos máximos, teniendo una puntuación máxima en los dos primeros criterios de buscabilidad e identidad, siendo respectivamente 5 y 8 puntos.

El criterio diseño-estilo puntuó 34,5 de un total de 39 puntos, la navegabilidad logró 27 puntos de 37 , y la seguridad alcanzó 3 puntos de un máximo de 8, porque en el Portal sólo se encontró el Certificado Digital.

TABLA 5. TEST HEURíSTICO - USABILIDAD GENERAL

\begin{tabular}{llcc}
\hline País & Brasil & España \\
\hline URL & & http://www.transparencia.gov.br/ & http://transparencia.gob.es/ \\
\hline Fecha análisis & & 18-06-2018 & 19-06-2018 \\
\hline 1. Buscabilidad & Puntuación Total Criterio 1 (sobre 5) & 5 & 5 \\
\hline 2. Identidad & Puntuación Total Criterio 2 (sobre 8) & 8 & 8 \\
\hline 3. Diseño-estilo & Puntuación Total Criterio 3 (sobre 39) & 33 & 34,5 \\
\hline 4. Navegabilidad & Puntuación Total Criterio 4 (sobre 37) & 27 & 27 \\
\hline 5. Seguridad & Puntuación Total Criterio 5 (sobre 8) & 0 & 3 \\
\hline & Total test & $\mathbf{7 4}$ & $\mathbf{7 7 , 5}$ \\
\hline
\end{tabular}

Fuente: Elaboración propia.

En cuanto al test de oferta informativa, en el caso de Brasil analizamos la herramienta Sistema Eletrônico de Informação ao Cidadão (e-SIC) ${ }^{7}$, como se ha señalado arriba, porque es el principal sistema de servicio para la solicitud de información. El portal puntuó 62 puntos de 64 máximos.

En el primer criterio, que trata de la parte institucional del sistema de información, obtuvo 19 puntos de 20. Referente al catálogo de servicios, alcanzó una puntuación máxima de 32 puntos. Para el tercer y cuarto criterio, que tratan de otras entidades y repositorios documentales, analizamos el Portal Acceso a la Información ${ }^{8}$ porque tales criterios están presentes en este portal que está vinculado al Portal da Transparência, al mismo tiempo que también conecta con la herramienta e-SIC.

Referente al criterio 3, existen informaciones de otras entidades nacionales e internacionales conectados al trabajo de la transparencia, obteniéndose 7 puntos de 8, porque dirige a otros canales de transparencia. Sin embargo, la propia administración pública no posee espacio o informaciones con relación a otras instituciones como la sociedad civil, por ejemplo.

En el último criterio sobre la disponibilidad de un repositorio de publicaciones, este tiene la puntuación máxima, pues pone a disposición una serie de estudios, informes y colecciones acerca de la temática de la transparencia.

En España, el primer criterio relativo al sistema institucional de información obtuvo 15 puntos de 20 máximos. En lo que respecta al criterio de servicios, obtuvo una puntuación de 32 puntos. El tercer criterio, que analiza si el Portal da acceso a otras entidades que tratan de la misma temática, puntuó 3,5 de 8 puntos. Y el cuarto criterio, que trata de repositorios documentales, puntuó 2 de 4 puntos máximos. Esto es debido a que existe un repositorio, pero no es comprensible y tampoco fácil de encontrarlo y acceder a él.

\footnotetext{
7 Acceso al Sistema Eletrônico de Informação ao Cidadão: https://esic.cgu.gov.br/sistema/site/index.aspx.

B Acceso al Portal Acceso a la Información: http://www.acessoainformacao.gov.br/.
} 
GAPP. Nueva Época - N. 24, noviembre 2020 - ISSN: 1989-8991 - DOI: https://doi.org/10.24965/gapp.i24.10776 - [Págs. 44-62]

TABLA 6. TEST HEURÍSTICO - OfERTA INFORMATIVA

\begin{tabular}{|c|c|c|c|}
\hline País & & Brasil & España \\
\hline URL & & $\begin{array}{l}\text { https://esic.cgu.gov.br/sistema/ } \\
\text { site/index.aspx e http://www. } \\
\text { acessoainformacao.gov.br/ }\end{array}$ & $\begin{array}{c}\text { http://transparencia.gob.es/ } \\
\text { transparencia/transparencia_ } \\
\text { Home/index.html }\end{array}$ \\
\hline Fecha análisis & & 20-06-2018 & $20-06-2018$ \\
\hline $\begin{array}{l}\text { 1. Institucional y del } \\
\text { sistema de información }\end{array}$ & $\begin{array}{l}\text { Máximos puntos posibles } \\
\text { APARTADO } 1(20 \mathrm{p})\end{array}$ & 19 & 15 \\
\hline $\begin{array}{l}\text { 2. Catálogo / relación } \\
\text { de servicios }\end{array}$ & $\begin{array}{l}\text { Máximos puntos posibles } \\
\text { APARTADO } 2 \text { ( } 28 \text { p.) }\end{array}$ & 28 & 28 \\
\hline 3. Otras entidades & $\begin{array}{l}\text { Máximos puntos posibles } \\
\text { APARTADO } 4 \text { ( } 8 \text { p.) }\end{array}$ & 7 & 3,5 \\
\hline \multirow[t]{2}{*}{$\begin{array}{l}\text { 4. Repositorios } \\
\text { documentales }\end{array}$} & $\begin{array}{l}\text { Máximos puntos posibles } \\
\text { APARTADO } 5 \text { ( } 4 \text { p.) }\end{array}$ & 4 & 2 \\
\hline & TOTAL TEST & 58 & 48,5 \\
\hline
\end{tabular}

Fuente: Elaboración propia.

En el tercer test, referente a la comunicación y participación ciudadana, volvemos a analizar el Portal da Transparência de Brasil, que obtuvo 19,5 puntos de 38 puntos máximos.

En el primer criterio de enlace, es decir, en las herramientas y servicios de participación ciudadana, se ha alcanzado 2,5 puntos de 3 puntos máximos.

En el segundo criterio, que analiza la atención al ciudadano con la disponibilidad de chats, email y buzón virtual, se obtienen 3 puntos de un máximo de 6, porque el Portal sólo aporta chat, no ofreciendo las otras opciones para el usuario.

Con respecto al tercer criterio referente al gobierno abierto, la puntuación fue 14 de 29 puntos máximos, pues la mayoría de los criterios no fueron cumplidos además de no ofrecer a los usuarios un mecanismo de discusión y debate por medio de blogs, foros y mapas colaborativos.

España a su parte logró 15,5 puntos de 38 puntos máximos. El criterio de enlace obtuvo la puntuación máxima de 3 puntos, el segundo criterio de atención ciudadana alcanza 2 puntos de 6 , porque el portal sólo posee buzón virtual, no poseyendo correo electrónico o Chat. En el tercer criterio, la puntuación fue 10,5 de un total de 29 puntos por las mismas razones que el portal de Brasil.

TABLA 7. TEST HEURÍSTICO - COMUNICACIÓN Y PARTICIPACIÓN CIUDADANA

\begin{tabular}{llcc}
\hline \multicolumn{1}{c}{ País } & \multicolumn{1}{c}{ Brasil } & España \\
\hline URL & & $\begin{array}{c}\text { http://www. } \\
\text { transparencia.gov.br/ }\end{array}$ & $\begin{array}{c}\text { http://transparencia.gob.es/transparencia/ } \\
\text { transparencia_Home/index.html }\end{array}$ \\
\hline Fecha análisis & $\mathbf{2 1 - 0 6 - 2 0 1 8}$ & $\mathbf{2 1 - 0 6 - 2 0 1 8}$ \\
\hline 1. Enlace & $\begin{array}{l}\text { Total dimensión 1 } \\
\text { (máximo: 3 puntos) }\end{array}$ & 2,5 & 3 \\
\hline 2. Atención ciudadana & $\begin{array}{l}\text { Total dimensión 2 } \\
\text { (máximo: 6 puntos) }\end{array}$ & 3 & 2 \\
\hline 3. Gobierno abierto & $\begin{array}{l}\text { Total dimensión 3 } \\
\text { (máximo: 29 puntos) }\end{array}$ & 14 & 10,5 \\
\hline & TOTAL TEST & $\mathbf{1 9 , 5}$ & $\mathbf{1 5 , 5}$ \\
\hline
\end{tabular}

Fuente: Elaboración propia. 
En el cuarto test, que analiza los servicios, volvemos a analizar la herramienta Sistema Eletrônico de Informação ao Cidadão (e-SIC) ${ }^{9}$, en la parte intranet, por los mismos criterios que en el segundo test. La puntuación fue 32 puntos, teniendo un resultado máximo en lo que se refiere al servicio de solicitud de información.

España también logró 32 puntos, la puntuación máxima, en lo que se refiere al servicio de solicitud de información que es intranet. La aplicación está estructurada pudiendo el usuario hacer todo el proceso por internet.

TABLA 8. Test heuRístico - SERVicios

\begin{tabular}{|c|c|c|c|}
\hline País & & Brasil & España \\
\hline URL & & $\begin{array}{l}\text { https://esic.cgu.gov. } \\
\text { br/sistema/site/index. } \\
\text { aspx }\end{array}$ & $\begin{array}{c}\text { http://transparencia.gob.es/transparencia/ } \\
\text { transparencia_Home/index/Derecho-de- } \\
\text { acceso-a-la-informacion-publica/Solicite- } \\
\text { informacion.html }\end{array}$ \\
\hline Fecha análisis & & 21-06-2018 & 18-07-2018 \\
\hline $\begin{array}{l}\text { 1. Registro en el } \\
\text { sistema }\end{array}$ & $\begin{array}{l}\text { Puntuación Total Criterio } 1 \\
\text { (sobre 12) }\end{array}$ & 12 & 12 \\
\hline $\begin{array}{l}\text { 2. Solitud de } \\
\text { información }\end{array}$ & $\begin{array}{l}\text { Puntuación Total Criterio } 2 \\
\text { (sobre 16) }\end{array}$ & 16 & 16 \\
\hline \multirow[t]{2}{*}{$\begin{array}{l}\text { 3. Reclamaciones } \\
\text { y Sugerencias }\end{array}$} & $\begin{array}{l}\text { Puntuación Total Criterio } 3 \\
\text { (sobre 4) }\end{array}$ & 4 & 4 \\
\hline & TOTAL TEST & 32 & 32 \\
\hline
\end{tabular}

Fuente: Elaboración propia.

\section{DISCUSIÓN Y ANÁLISIS COMPARATIVO}

Como ya vimos anteriormente, el Portal de transparencia de España es menos confuso y mejor estructurado que el de Brasil, que posee un sistema de portales que conecta diferentes contenidos. Sin embargo, presenta algunas dificultades al usuario como, por ejemplo, la dificultad de registro en el sistema clave.

En casi todos los test, los portales necesitan mejorar, teniendo su mejor desarrollo en el test de servicios en el que se obtiene la puntuación máxima, porque al término, es donde está la aplicación de las leyes de manera más concreta. Sin embargo, los resultados del test de usabilidad nos muestran que todavía faltan aspectos que mejorar para facilitar la navegación del usuario en el Portal.

Por su parte, el test de oferta informativa revela que es necesario organizar mejor las informaciones del sitio para que sean más visibles y mejor definidos el catálogo de servicios, es decir, que estén mejor identificados los servicios e informaciones ofertados por los portales.

La parte de comunicación es la más crítica. Los portales alojan recursos sencillos, pero tienen un rendimiento por debajo de las expectativas con relación a las herramientas de discusiones y colaboración como blogs y foros, e incluso en el uso de las redes sociales, que son capaces en un mundo digital de llegar hasta el usuario de forma creativa, generando interés y así responsabilidad cívica.

De manera general, cuando comparamos los dos portales, observamos que presentan problemas muy parecidos, no teniendo mucha diferencia entre ellos en los resultados en la puntuación de los test. En este sentido, lo más importante es que el diseño de la estructura de los portales es muy parecido en los dos países, no siendo la estructura un problema.

La organización del Portal de Transparencia español está bien, pues es menos confuso y mejor organizado. La página inicial tiene menos información, pero son fácilmente identificables los asuntos deseados y, al hacer clic en éstos, las pestañas se abren como parte del portal y no como nuevos portales, como pasa en Brasil.

\footnotetext{
9 Acceso al Sistema Eletrônico de Informação ao Cidadão: https://esic.cgu.gov.br/sistema/site/index.aspx.
} 
Por otro lado, si se analizan los apartados de interacciones de los portales, se hace más nítida la necesidad de más herramientas para actuación por parte de la sociedad organizada. Es importante tener un espacio en los portales que faciliten el trabajo conjunto para que, al final, las discusiones sobre las temáticas de control social, responsabilidad y buen gobierno lleguen a todos los sectores de la sociedad, influyendo así en la participación de los ciudadanos, en las discusiones de interés público y llevando a cabo la soñada ciudadanía.

Las leyes y los portales son importantes, pero no suficientes para generar la práctica de la ciudadanía. Estos sí, son capaces de facilitarla, pues, como hemos podido comprobar, en los portales, a pesar de los problemas, las informaciones se encuentran online, la usabilidad existe y es una herramienta facilitadora.

Las leyes se aplican en los dos casos, pero para lograr un bueno gobierno es necesario que Brasil y España vayan más allá. Es importante que los ciudadanos accedan a los portales, miren las informaciones, las debatan y que puedan, al fin, influir en las políticas públicas y así moldear el comportamiento del Estado. La transparencia precisa convertirse en un indicador eficiente que garantiza la práctica de la ciudadanía.

Para eso, es necesaria la creación de un sistema orgánico en que haya participantes del Estado y de la sociedad, que se autoalimente teniendo a las personas como parte principal para generar un comportamiento que logre al buen gobierno, y, al mismo tiempo, que el Estado tenga un comportamiento de buen gobierno con relación a la disponibilidad de información.

Los dos países están haciendo solamente el mínimo esperado, dado que la aplicación de la ley no significa un buen gobierno. Para que se logre el buen gobierno, es necesario que esta aplicación corresponda a las demandas y expectativas de los ciudadanos. Más allá de eso, es necesario posibilitar espacios de discusión y participación efectiva, atrayendo a las personas, haciendo que se sientan parte del proceso, para que al final se conquisten prácticas efectivas de buen gobierno.

\section{CONCLUSIÓN}

La investigación se desarrolló a partir del objetivo de analizar la aplicación de las leyes de transparencia de Brasil y España, en una perspectiva comparada y analizar el nivel de usabilidad de los sitios institucionales de los gobiernos de Brasil y España para conocer, los mecanismos alojados en estas webs que facilitan el acceso de la ciudadanía a la información y comprobar el grado de aplicación de las leyes de transparencia.

En este trabajo, hemos observado que la cuestión de la transparencia se conecta a muchos otros conceptos y, para que la transparencia sea reconocida como un derecho y así sea llevada a cabo como parte de la práctica de la ciudadanía, es necesario mucho más que practicas sencillas. Es necesaria una profunda discusión que involucre conceptos importantes como democracia, gobernanza y tecnología.

Desde el punto de vista de las leyes, la transparencia es un derecho, en Brasil previsto por la Constitución como derecho fundamental. Años después de la promulgación de las dos constituciones, tanto en Brasil como en España, surgieron leyes para garantizar el derecho al acceso a la información pública.

En Brasil se aprobó la Lei de Acesso à Informação (Lei n. ${ }^{\circ}$ 12.527/2011 - LAI) y en España la Ley de Transparencia, Acceso a la Información Pública y Buen Gobierno (Ley 19/2013), respectivamente, en 2011 y 2013. Con respecto a este derecho, en Brasil la transparencia es percibida como algo necesario para la práctica de la ciudadanía, que está en consonancia con el artículo 19 de la Declaración Universal de los Derechos Humanos. En España, si bien hay referencias a este derecho en la Constitución, éste es más subjetivo cuando se trata de su naturaleza jurídica para guiar la creación de las Políticas Públicas (Villanueva Cuevas, 1993; Torreblanca López, 2002; Martos, 2016, citado por Santos et al. 2017: 50).

La historia del proceso de elaboración de las leyes, como miramos en el segundo apartado, nos presenta que, no es resultado de presión popular y sí de una necesidad reconocida por los gobiernos. La construcción de ninguna de las leyes fue por medio de un proceso bottom-up, es decir, presión por parte de la población, sino por top-down, por iniciativa del Estado. No hubo, de este modo, una presión social suficientemente fuerte para causar impacto en la decisión de construcción de las leyes, sino que las dos fueron iniciativa del Estado bajo cierta influencia internacional. Además, es interesante observar cómo países con sistemas políticos, sociales y económicos distintos, poseen un proceso paralelo en la construcción de la ley de transparencia desde una perspectiva top-down.

Las leyes, a pesar de sus problemas estructurales, mejoran la situación anterior. Pero, para que funcionen como las teorías esperan, es necesario también interés por parte de la sociedad, exigiéndolas como un derecho, vigilando los portales y las acciones de los gobernantes (Cotino-Hueso, 2014: 256). La aplicación 
de las leyes no sólo se dirige a mejorar la trasparencia y el control social, también debe facilitar la participación y así llevar a cabo la creación de políticas públicas y servicios innovadores por medio de un sistema inteligente de colaboración (Márquez, 2014 citado por Villoria, 2015: 86).

Al final, como nos muestra el trabajo, existe sí, una relación entre Transparencia y Ciudadanía, en el sentido de que la transparencia facilita la práctica de la ciudadanía, pues tener información pública accesible es un importante recurso, y los portales, por cómo están estructurados, a pesar de sus limitaciones, son herramientas capaces de colaborar en la práctica de la ciudadanía.

Sin embargo, los portales fallan en la parte de comunicación y espacios de participación ciudadana para Ios usuarios: estos mecanismos, cuando se trata de transparencia, son herramientas muy interesantes para fomentar el debate y el control social de manera más fluida e informal, pudiendo también llegar al usuario de forma creativa. Así, llevando a cabo nuestro objetivo, comprobamos que hay aplicación de la ley en los dos países. Esto acontece de manera aceptable y esperada, pero todavía falta más: faltan mejoras, falta la creación de un sistema que se autoalimente contando con ciudadanos que influyan en las acciones del Estado, al mismo tiempo que exista un Estado que posibilite espacios y atraiga a los ciudadanos para las discusiones públicas, logrando así el conocido buen gobierno.

Es importante tener en cuenta que crear los medios para el acceso a la información con garantías mínimas de publicidad activa, no es suficiente ya que no desarrollan por si solo otros valores cívicos, como el valor cultural de la ciudadanía y, tampoco mejoran la calidad de la democracia. Es necesario, por lo tanto, que haya iniciativas públicas comprometidas con la transparencia y control social que pongan en marcha técnicas y articulen espacios de empoderamiento ciudadano.

\section{REFERENCIAS BIBLIOGRÁFICAS}

ÁLVAREZ, E. (2013): “Una reflexión sobre transparencia y buen gobierno”, en Revista Cuadernos Manuel Giménez Abad, núm. 5, págs. 214-229. Fecha de consulta: 14-03-2018. URL: https://dialnet.unirioja.es/servlet/ articulo?codigo $=4347898$.

BARROS, A. (2015): "O projeto de transparência do Senado Federal: entre a accountability e a propaganda política”, en Revista Sociologias, núm. 39, págs. 338-368. Fecha de consulta: 12-03-2018. URL: http://www.scielo.br/ scielo.php?pid=S1517-45222015000200338\&script=sci_abstract\&t/ng=pt. DOI: $h$ ttps://doi.org/10.1590/15174522017003913.

BARROS, A.; BERNARDES, C.; REHBEIN, M. (2014): "Visibilidade e epresentação política: o caso da Câmara dos Deputados no Brasil", en Revista Contextualizaciones Latinoamericanas, vol. 6, núm. 10, págs. 1-13. Fecha de consulta: 14-03-2018. URL: http://www.revistascientificas.udg.mx/index.php/CL/article/view/2772/2514.

BOUZAS, R.; MAHOU, X. (2013): "El estudio de la funcionalidad de los portales gubernamentales: Una propuesta metodológica desde la e-salud”, en Revista Gestión y Política Pública, vol. 22, núm. spe, págs. 259-305. Fecha de consulta: 01-03-2018. URL: http://www.scielo.org.mx/scielo.php?script=sci_abstract\&pid=S1405$10792013000400008 \&$ lng=es\&nrm=iso.

CASTELLS, M. (2001): La era de la información. La sociedad red. Madrid: Alianza. 2. a ed.

COMISIÓN PARA LA REFORMA DE LAS ADMINISTRACIONES PÚBLICAS (CORA) (2013): Reforma de las Administraciones Públicas. Gobierno de España: Ministerio de Hacienda y Administraciones Públicas; Ministerio de la Presidencia. Fecha de consulta: 03-04-2020. URL: https://transparencia.gob.es/transparencia/dam/ jcr:b1c69477-9882-41a5-9f6d-5cbb46fa12b4/reforma-AAPP.PDF.

COTINO-HUESO, L. (2014): "La nueva Ley de transparencia y acceso a la información”, en Anuario de la Facultad de Derecho (Universidad de Alcalá), núm. 7, págs. 241-256. ISSN: 1888-3214. Fecha de consulta: 12-03-2018. URL: https://ebuah.uah.es/dspace/handle/10017/22075.

CRIADO, I. (2016): "Las administraciones públicas en la era del gobierno abierto. Gobernanza inteligente para un cambio de paradigma en la gestión pública", en Revista de Estudios Políticos, núm. 173, págs. 245-275. Fecha de consulta: 12-07-2018. URL: https://recyt.fecyt.es/index.php/RevEsPol/article/view/52490. DOI: http://dx.doi. org/10.18042/cepc/rep.173.07.

DAGNINO, E. (2004): "Sociedade civil, participação e cidadania: de que estamos falando?", en MATO, D. (coord.): Políticas de ciudadania y sociedade civil en tiempos de globalización, págs. 95-110. Caracas: FaCES; Universidad Central de la Venezuela. Fecha de consulta: 07-07-2018. URL: http://biblioteca.clacso.edu.ar/Venezuela/facesucv/20120723055520/Dagnino.pdf.

DALLARI, D. A. (1998): Direitos Humanos e Cidadania. São Paulo: Moderna, 1. a ed.

ESPAÑA (1978): "Constitución Española”, en Boletín Oficial del Estado (BOE), 29 de diciembre de 1978, núm. 311, pág. 32. Madrid: Boletín Oficial del Estado (BOE). Fecha de consulta 02-03-2018. URL: https://www.boe.es/ legislacion/documentos/ConstitucionCASTELLANO.pdf. 
ESPAÑA (2013): "Ley 19/2013, de 9 de diciembre, de Transparencia, Acceso a la Información Pública y Buen Gobierno", en Boletín Oficial del Estado (BOE), núm. 295. Madrid: Boletín Oficial del Estado (BOE). Fecha de consulta 02-03-2018. URL: https://www.boe.es/buscar/doc.php?id=BOE-A-2013-12887.

ESPÍN LÓPEZ, S. M. (2017): Políticas públicas y relaciones intergubernamentales: un estudio de caso. Tesis Doctoral. Murcia: Universidad de Murcia. Fecha de consulta: 31-03-2018. URL: http://hdl.handle.net/10201/56611.

EVANGELISTA, L. (2010): Controle social versus transparência pública: uma questão de cidadania. Especialización en Presupuesto Público. Brasília:Tribunal de Contas da União. Fecha de consulta: 21-03-2018. URL: https://portal. tcu.gov.br/biblioteca-digital/controle-social-versus-transparencia-publica-uma-questao-de-cidadania.htm.

JARDIM, J. M. (2012): "A Lei de acesso à informação pública: dimensões político-informacionais", en Encontro Nacional de Pesquisa em Ciência da Informação. Celebrado en Rio de Janeiro, el 28-30 de octubre de 2012. Rio de Janeiro: XIII encuentro ENANCIB. Fecha de consulta: 12-03-2018. URL: http://repositorios.questoesemrede.uff. br/repositorios/handle/123456789/1736?show=full.

LEÓN, C.; GARZA, E. A. (2014): "Método comparativo”, en SÁENZ LÓPEZ, K.; TAMEZ GONZÁLEZ, G. (coords.): Métodos y técnicas cualitativas y cuantitativas aplicables a la investigación en Ciencias Sociales, págs. 223-251. México: Tirant Humanidades México.

MAHOU, X. M.; VARELA-ÁLVAREZ, E. (2015): "Innovation and opportunities for citizen participation in Spanish smart cities", en GIL-GARCIA, R. J. et al. (eds.): Smarter as the New Urban Agenda: A Comprehensive View of the 21st Century. Heidelberg, New York, London: Springer.

OECD (2003): "Open Government: Fostering Dialogue with Civil Society", en OECD: Public Sector Modernization: Open Government. Paris: OECD Publishing. Fecha de consulta: 15-03-2018. DOI: https://doi. org/10.1787/9789264019959-en.

PAES, E. B. (2011): "A construção da lei de acesso à informação pública no Brasil: desafios na implementação de seus princípios", en Revista do Serviço Público, vol. 62, núm. 4, págs. 407-423. Fecha de consulta: 17-06-2018. URL: https://revista.enap.gov.br/index.php/RSP/article/view/80. DOI: https://doi.org/10.21874/rsp.v62i4.80.

PIÑAR MAÑAS, J. L. (2014): "Transparencia y derecho de acceso a la información pública. Algunas reflexiones en torno al derecho de acceso en la Ley 19/2013, de Transparencia, Acceso a la Información y Buen Gobierno", en Revista catalana de Dret Públic, núm. 49, págs. 1-19. Fecha de consulta: 10-03-2018. URL: http://revistes. eapc.gencat.cat/index.php/rcdp/article/viewFile/10.2436-20.8030.01.29/n49-pinar-es.pdf. DOI: https://doi. org/10.2436/20.8030.01.29.

RAMÍREZ-ALUJAS, A. V. (2011): "Gobierno Abierto y Modernización de la Gestión Pública. Tendencias actuales y el (Inevitable) Camino que Viene - Reflexiones Seminales", en Revista Enfoques: Ciencia Política y Administración Pública, vol. IX, núm. 15, págs. 99-125. Fecha de consulta: 14-03-2018. URL: https://papers.ssrn.com/sol3/papers. cfm?abstract id=1979133.

REPÚBLICA FEDERATIVA DE BRASIL (1988): Constituição da República Federativa do Brasil. Brasilia, DF: Senado Federal. Fecha de consulta 02-03-2018. URL: http://www.planalto.gov.br/ccivil_03/constituicao/constituicao.htm.

REPÚBLICA FEDERATIVA DE BRASIL (2011): Lei n. ${ }^{\circ} 12.527$, de 18 de novembro de 2011. Regula o acesso a informações previsto no inciso XXXIII do art. 5. ${ }^{\circ}$, no inciso II do $\S 3 .^{\circ}$ do art. 37 e no $\S 2 .^{\circ}$ do art. 216 da Constituição Federal; altera a Lei $n .^{\circ} 8.112$, de 11 de dezembro de 1990; revoga a Lei $n .{ }^{\circ} 11.111$, de 5 de maio de 2005, e dispositivos da Lei n. ${ }^{\circ} 8.159$, de 8 de janeiro de 1991; e dá outras providências. Brasilia, DF: Presidência da República, Casa Civil, Subchefia para Assuntos Jurídicos. Fecha de consulta 02-03-2018. URL: http://www. planalto.gov.br/ccivil_03/_ato2011-2014/2011/lei//12527.htm.

SANTOS, J.; MOLINA, J.; GUIMARÃES, J. (2017): "Direito de Acesso à Informação: uma análise a partir das realidades espanhola e brasileira", en Revista Informação \& Sociedade: Estudos, vol. 27, núm. 2, págs. 49-62. Fecha de consulta: 12-03-2018. URL: http://periodicos.ufpb.br/ojs/index.php/ies/article/view/31196. DOI: https:// doi.org/10.22478/ufpb.1809-4783.2017v27n2.31196.

SHRIVASTAVA, A. (2015): Theory of Transparency: The Right to Know, short article. Dehradun: University of Petroleum and Energy Studies. Fecha de consulta: 15-07-2018. URL: http://works.bepress.com/amartya_shrivastava/1/.

VASCONCELOS NETO, F. (2015): "Transparência e Acesso à Informação: da cidadania de direitos ao exercício das obrigações”, en VII Jornada Internacional Políticas Públicas, págs. 143-169. Celebrado en São Luis/Maranhão (Brasil), el 25-28 de agosto de 2015. Universidade Federal do Maranhão, Centro de Ciencias Socias, Programa de Pós-Gradução em Políticas Públicas. Fecha de consulta: 13-03-2018. URL: http://www.joinpp.ufma.br/ jornadas/joinpp2015/pdfs/eixo3/transparencia-e-acesso-a-informacao-da-cidadania-de-direitos-ao-exercicio-dasobrigacoes-.pdf.

VILLORIA, M. (2015): "La transparencia como política pública en España: algunas reflexiones", en Revista en Cultura de la Legalidad, núm. 7, págs. 85-103. Fecha de consulta: 13-03-2018. URL: https://e-revistas.uc3m.es/index.php/ EUNOM/article/view/2234/1170. DOI: https://doi.org/10.20318/eunomia.2019.4697. 